\title{
EXTRACTION, ISOLATION AND EVALUATION TRIGONELLA FOENUM-GRAECUM AS MUCOADHESIVE AGENT FOR NASAL GEL DRUG DELIVERY
}

\author{
Dharmendra Kumar ${ }^{*}$, Aditi Singhal, Sumedha Bansal, S.K Gupta
}

Department of Pharmaceutical Technology, Meerut Institute of Engineering and Technology,

Meerut, Uttar Pradesh, India, 250005

\begin{abstract} levels.

*Corresponding Author:

Dharmendra Kumar

Department of Pharmaceutical Technology,

Meerut Institute of Engineering and Technology,

Meerut, Uttar Pradesh, India, 250005

Email: rvnimiet@gmail.com
\end{abstract}

The purpose of the study is to formulate and evaluate a new, cheap and effective natural mucoadhesive agent that can be used as an effective alternative for traditional mucoadhesive agent. The study procedure involved extraction of mucoadhesive agent from the Trigonellafoenumgraecum (fenugreek) seeds, solubility testing of the mucilage obtained, phytochemical testing, determination of swelling index, preparation of nasal gel, measurement of viscosity, The study showed that the extraction of fenugreek seeds had $36 \% \mathrm{w} / \mathrm{w}$ of mucoadhesive agent. The natural mucoadhesive agent was soluble in hot water and cold water.The swelling index was found to be $160 \%$.Fenugreek seeds produce high viscosity mucilage at low concentration

Keywords:TrigonellaFoenumGraecum, Mucoadhesive Agent, Nasal Gel Drug Delivery, 


\section{INTRODUCTION}

Trigonellafoenum-graecum $L$. (Fenugreek) belongs to the Leguminosae family. It is an annual grassy plant Fenugreek seeds have been widely used in food as a flavour component and seasoning.

In clinical, Fenugreek seeds are reported to have glucose and lipid-lowering properties. Phytochemical studies on $\mathrm{T}$. foenum-graecum revealed that carbohydrates and mucilages (mainly galactomannans), proteins, fixed oils, flavonoids and saponins were the main components of the seeds.

Fenugreek is known to have several pharmacological effects such as hypoglycemic, hypocholestrolemic, antioxidant, and appetite stimulation. Furthermore, this plant has gastro protective activity5 and histopathological examination of liver and brain has revealed that, aqueous extract of fenugreek seeds offer a significant protection against ethanol toxicity.

Fenugreek has been used in treating colic flatulence, dysentery, diarrhoea, dyspepsia with loss of appetite, chronic cough, dropsy, enlargement of liver and spleen, rickets, gout, and diabetes. It is also used as gastro protective, antiurolithiatic, diuretic, antidandruff agent, Anti-inflammatory agent and as antioxidant. The seed is stated to be a tonic. It also is used in post-natal care and to increase lactation in nursing mothers. Fenugreek seeds contain a high percentage of mucilage.

Since Fenugreek seeds produce high viscosity mucilage at low concentration levels, the objective of the present investigation was to evaluate the mucoadhesive effects of this mucilage in nasal gel.

\section{MATERIALS AND METHODS}

\section{Chemicals}

Acetone, and other required materials provide by department of pharmaceutics MIET Meerut.

\section{Plant material}

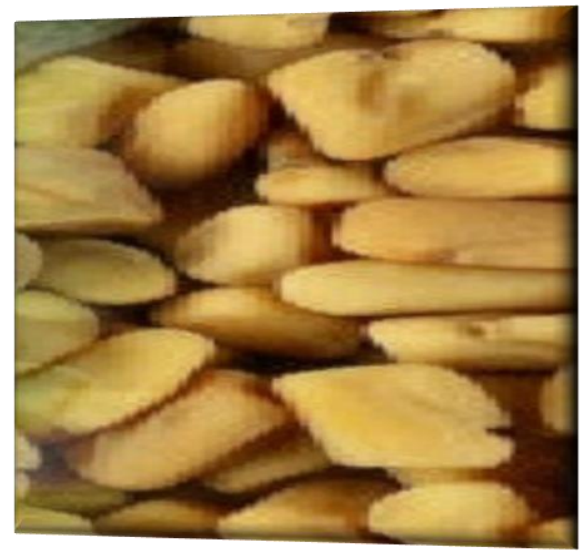

The seeds of Fenugreek were purchased from local market, Ghanghauli, Super Noida, India. The seeds were identified and authenticated by MIET Meerut.

\section{METHODS}

\section{Extraction and Isolation of Mucoadhesive Material [7]}

Fenugreek seeds ( $250 \mathrm{~g}$ ) were soaked in double distilled water at room temperature and then boiled with sufficient amount of double distilled water under stirring condition in a water bath until slurry was prepared. Then the slurry was cooled and kept in refrigerator overnight to settle out un- 
dissolved materials. The upper clear solution was decanted off and centrifuged at $1000 \mathrm{rpm}$ for 30 minutes. The supernatant was separated and concentrated at $50-55^{\circ} \mathrm{C}$ on a water bath to a third of its original volume. Solution was cooled down to room temperature and was poured into thrice volume of acetone by continuous stirring. The precipitate was washed repeatedly with acetone and dried.

\section{Determination of percentage yield}

$\%$ Yield $=$ Practical Yield $* 100 /$ Theoretical Yield

Physico-chemical characterization of mucilage [8-10].The separated mucilage was evaluated for solubility, swelling index, loss on drying, ash value, microbial load, density, compressibility index and angle of repose.

\section{Fourier Transform Infrared (FTIR) Spectroscopy}

FTIR spectra were recorded on samples prepared in potassium bromide $(\mathrm{KBr})$ disks using a Shimadzu FTIR instrument. Samples were prepared in $\mathrm{KBr}$ disks by means of a hydrostatic press at 6-8 tons pressure. The scanning range was 500 to $4500 \mathrm{~cm}^{-1}$

\section{Viscosity Determination}

One (1) g of dried and finely powdered fenugreek mucilage was suspended in $75 \mathrm{ml}$ of distilled water for $5 \mathrm{~h}$. Distilled water added up to $100 \mathrm{ml}$ to produce the concentration of $1 \% \mathrm{w} / \mathrm{v}$. The mixture was homogenized by mechanical stirrer for $2 \mathrm{~h}$ and its viscosity determined using a Brookfield viscometer, at $37^{\circ} \mathrm{C}$.

Viscosity of suspending agent $\eta_{1}=\eta_{2} X\left(\rho_{1} t_{1} / \rho_{2} t_{2}\right)$

Determination of Swelling Index [11]

\section{Method I}

The swelling index is the volume in $\mathrm{ml}$ occupied by $1 \mathrm{~g}$ of drug; including any adhering mucilage after it has been swollen in an aqueous liquid for $4 \mathrm{~h}$. The swelling index of Fenugreek mucilage powder, was determined according to the BP method. One gram of mucilage powder was taken in a $25 \mathrm{ml}$ ground glass stoppered cylinder graduated over a height of 120 to $130 \mathrm{~mm}$ in 0.5 divisions. To this $25 \mathrm{ml}$ of water was added and this was shaken vigorously every $10 \mathrm{~m}$ for $1 \mathrm{~h}$ and then allowed to stand for $24 \mathrm{~h}$. The volume occupied by mucilage was measured. The Swelling index was calculated from the mean of three determinations.

Method II

The natural suspending agent $1 \mathrm{~g}$ was taken in a China dish and then $10 \mathrm{ml}$ of distilled water was added and the mixture was shaken and allowed to stand for 1 hour. After 1 hour the remaining water in China dish was discarded and the weight increase of the natural suspending agent was rated.

Swelling Index \% (SI) = (W2 - W1/W1) x 100 -------- (1)

$\mathrm{W} 1=$ Weight of powder at time ' 0 '

$\mathrm{W} 2=$ Weight of powder at time' $\mathrm{t}$ '

\section{Solubility}

Solubility of isolated mucilage was studied using different types of solvents like water, alcohol acetone, Polyethylene Glycols, Propylene Glycol, Glycerin, Sorbitol, Ethyl Alcohol, Methanol, Benzyl Alcohol and Isopropyl Alcohol. 


\section{Hausner ratio}

Hausner calculated as the ratio of bulk density to tapped density. The Hausner ratio values less than 1.25 indicate good flow, while the values greater than 1.5 will show poor flow

\section{Angle of repose}

The flow ability of the powder was simply measured by determination of the angle of repose $(\theta)$ using fixed funnel method. The mucoadhesive powder was allowed to flow through the funnel onto the graph paper. The radius (r) and the height (h) of the cone formed on the paper permitted the determination of the angle of repose using eq.

\section{Determination of density}

$$
\operatorname{Tan}(\theta)=\mathrm{h} / \mathrm{r} \text {. }
$$

The bulk density $(\mathrm{Vb})$ was determined by filling $50 \mathrm{~g}$ granules into a graduated cylinder and calculating the ratio of the sample weight to sample volume. The tapped density (Vt) was determined as the ratio of the sample weight to the final sample volume.

\section{Result and discussion}

\section{Determination of percentage yield}

After drying mucilage weight $=90 \mathrm{~g}$ (practical yield)

Theoretical Yield $=250 \mathrm{~g}$

$\%$ Yield $=$ Practical Yield $* 100 /$ Theoretical Yield

$\%$ Yield $=90 * 100 / 250=36$.

\section{Fourier Transform Infrared (FTIR) Spectroscopy}

FTIR spectra were recorded on samples prepared in potassium bromide $(\mathrm{KBr})$ disks using a Shimadzu FTIR instrument. Samples were prepared in $\mathrm{KBr}$ disks by means of a hydrostatic press at 6-8 tons pressure. The scanning range was 500 to $4500 \mathrm{~cm}^{-1}$.

\section{Figure FTIR}

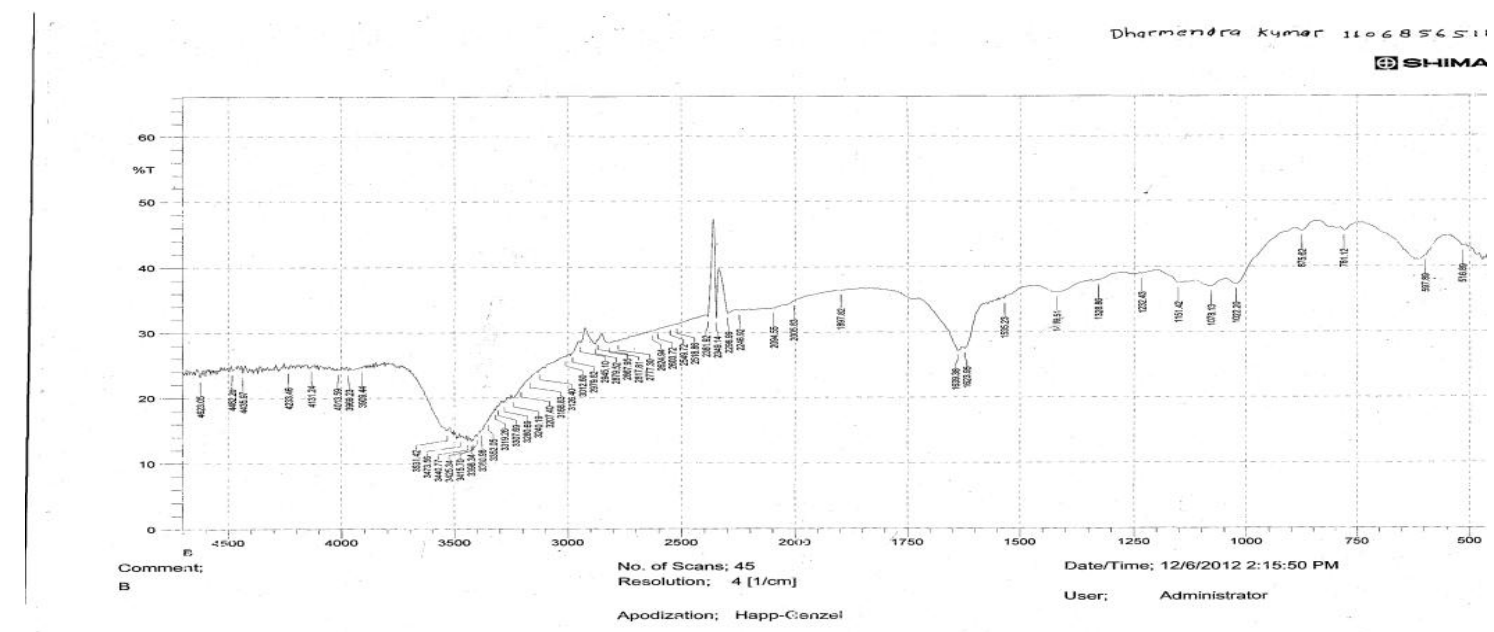

The absence of sharp peak at $1700-1800 \mathrm{~cm}^{-1}$ in the FTIR spectrum indicates that there is no carboxyl group in the extracted sample. On the other hand, the presence of peak at $1000-1200 \mathrm{~cm}^{-1}$ corresponds to the presence of alcoholic group mostly secondary alcohols. These findings proved that there were no uronic sugars or esters in the structure (Figure FTIR). 


\section{Determination of angle of repose}

The mucoadhesive powder was allowed to flow through the funnel onto the graph paper. The radius ( $r$ ) and the height $(h)$ of the cone formed on the paper permitted the determination of the angle of repose using eq.

$$
\begin{gathered}
\operatorname{Tan}(\theta)=\mathrm{h} / \mathrm{r} . \\
\mathrm{h}=1.7 \mathrm{~cm} \\
\mathrm{r}=3.03
\end{gathered}
$$

Angle of repose $(\theta)=29.29^{\circ}$.

on the basis of relationship between angle of repose $(\theta)$ and powder flow. The angle of repose was found to $\operatorname{good}(29.29)$.

\section{Swelling index}

Swelling index was determined was two methods. And the observation's was presented as.

Methods I - swelling index was found to be $9 \pm 0.2$.

Method II

Swelling Index \% (SI) $=(\mathrm{W} 2-\mathrm{W} 1 / \mathrm{W} 1) \times 100$

$\mathrm{W} 1=$ Weight of powder at time ' 0 '

$\mathrm{W} 2=$ Weight of powder at time' $\mathrm{t}$ '

$\mathrm{W} 1=10 \mathrm{~g}, \mathrm{~W} 2=26, \mathrm{SI} \%=160$.

Result shows that the time increase, swelling index was increased, because weight gain by mucilage was proportional to rate of hydration. The direct relationship was observed between swelling index and mucilage concentration, as mucilage concentration increase swelling index increased.

\section{Determination of $\mathbf{p H}$ and viscosity}

$\mathrm{pH}$ of $1 \%$ solution was found to be $6.23 \pm 0.2$. And viscosity was observed $39 \mathrm{cp}$ at $37^{\circ} \mathrm{C}(1 \%$ solution).

Physico-chemical characterization of mucilage

\begin{tabular}{ll}
\hline Parameters & Results \\
\hline Colour & Creamy yellowish \\
Taste & Tasteless \\
Odor & Odorless \\
State & Powder \\
Identification & \\
a. Mounted in 96\% ethanol & Transparent angular masses \\
b. Mounted in Ruthenium red & Particles stained red \\
c. Mounted in iodine solution & Particles stained blue \\
Test for carbohydrate (Mollish's test) & + \\
Test for tannins (Ferric chloride test) & - \\
Test for chloride (silver nitrate test) & - \\
Test for sulphate (Barium chloride test) & - \\
Total bacterial count & \\
E.coli & Absent \\
S.aureus & Absent \\
Salmonella typhi & Absent \\
\hline
\end{tabular}




\begin{tabular}{ll}
\hline Parameters & Results \\
\hline Solubility in water & Soluble in water (cold less, hot more), \\
Angle of repose & $29.29^{\circ}$ \\
Bulk density & 0.47 \\
Tapped density & 0.52 \\
pH & $6.23 \pm 0.2$. \\
True density & $1.4 \mathrm{~g} / \mathrm{dl}$ \\
Viscosity $(1 \%)\left(37^{\circ} \mathrm{C}\right)$ & $39 \mathrm{cp}$ \\
Hausner ratio & 1.10 \\
Swelling Index & $9 \pm 0.2($ Method I); $160($ Method II) \\
\hline
\end{tabular}

\section{CONCLUSION}

The extracted mucilagenous substance of Trigonellafoenumgraecum is edible, has the potential as a mucoadhesive agent even at lower concentration (1-3\% w/v). So fenugreekmucoadhesive is use in nasal gel formulations with low toxicity, high viscosity. So in future fenugreek mucoadhesive agent will use in nasal gel formulations with various drugs.

\section{REFERENCE}

1. Senthil , V. Sripreethi, D. Formulation and Evaluation of Paracetamol Suspension from TrigonellaFoenumGraecum Mucilage Journal of Advanced Pharmacy Education \& Research 2011, 1(5) 225-233.

2. TavakoliNaser, Varshosaz Jaleh et al Evaluation of TrigonellaFoenum- Graecum seeds gum as a novel Tablet binder Int J Pharm PharmSci, 2012, 1(4), 97-101.

3. Niraimathi K L ,Lavanya $\mathrm{R}$ et al Standardization studies on herbal binders and preservatives Journal of Pharmacy Research 2012,5(4),2091-2093.

4. Kumar Ravi, Patil Swati et al Isolation and Evaluation of Disintegrant Properties of Fenugreek Seed Mucilage Int.J. PharmTech Res.2009,1(4), 982-996.

5. Kumar Dharmendra, BansalSumedha . Nasal Drug Delivery System: A Complete Review bioscience (Pharma tutor)2013, Pharmatutor-ART-1593.

6. Kumar Dharmendra, Bansalmayank, Nasal Gel Formulation: A Review TGJPR 2012. P.g.303310.

7. DattaRimi, Bandyopadhyay A.K., Development of a new nasal drug delivery system of Diazepam using natural mucoadhesive agent from TrigonellaFoenumGraecum J SciInd Res 2005, 64, 973-977.

8. Kokate CK, Purohit AP, Gokhale SB. Pharmacognosy., 24th ed. Pune; Nirali Prakashan: 2003; 109.

9. Indian Pharmacopoeia. 4th ed. Ministry of health and family welfare, Govt. of India, NewDelhi; Controller of publications: 1996; A- 54.

10. British Pharmacopoeia. Volume 2, 2000; A- 207, 210.

11. British Pharmacopoeia Vol. II, Her Majesty’s Stationery Office, London, 1988: 140. 